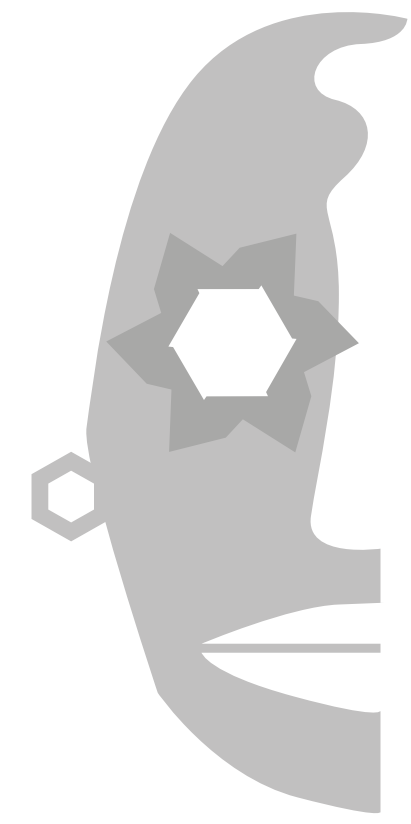

Catherine Poupeney-Hart Universidad de Montreal Canadá

\section{La prensa temprana en la era digital: contexto y} recursos

\section{Resumen:}

El estudio de la prensa periódica temprana en Hispanoamérica enfrenta al investigador con notables obstáculos debidos al tamaño del material y a su estatuto menor como práctica escritural que hizo que no se preservara en forma íntegra y en condiciones idóneas. Aunque falta mucho para que se generalicen, las operaciones de digitalización que llevan a cabo bibliotecas y archivos suponen una transformación radical de este panorama y unas implicaciones difíciles todavía de apreciar. Se completa un estado provisional y práctico de la cuestión con el examen, desde esta perspectiva, de la tercera serie de la Gaceta de Guatemala (1797-1807), órgano de prensa más importante al final del siglo XVIII y principios del XIX en Hispanoamérica.

Palabras clave: prensa temprana, reedición digital, discurso colonial, Ilustración, literatura centroamericana, Gaceta de Guatemala

\begin{abstract}
:
The main obstacle to the study of the early periodical press has been access to the materials, due in part to their volume, but even more to their minor status as a scriptural practice. More particularly in Hispanic America, this prevented several newspaper series from being preserved intact and what survived was not always kept in optimal conditions. Even if we will have to wait until relevant libraries or archives provide digitized version of their full collections, the operations that have already taken place offer unprecedented access to materials with potential implications still difficult to foresee. This article aims
\end{abstract}


initially to provide a brief and practical survey of the present situation. It will then move on to examine, from this perspective, the third series of the Gazeta de Guatemala (1797-1807), the most important newspaper at the end of the 18th and beginning of the 19th centuries in Hispanic America.

Keywords: early periodical press, electronic publishing, colonial discourse, Enlightenment, Central American literature, Gaceta de Guatemala

\section{Introducción}

El estudio de la prensa temprana desde la historia, la literatura o la comunicación, como disciplinas académicas, ha implicado enfrentarse, hasta ahora, con el problema de acceso a los textos. Nos referimos aquí en particular a la producción periodística que, para el ámbito hispanoamericano, parte del primer decenio del siglo XVIII y conoce un florecimiento notable durante la fase final del dominio incontestado de España sobre sus provincias ultramarinas, es decir, hasta la invasión napoleónica de la Península. Si la comparamos con formas de expresión más convencionalmente literarias, la periodística no ha sido lo suficientemente estudiada ni difundida y, en varios casos, no ha sido conservada en su integridad. Esto se debe en primera instancia al mediocre estatus social de un medio no avalado por la tradición clásica, ni por el prestigio de un autor único, y por lo tanto no es considerado digno de ser preservado con las mismas precauciones que otros impresos asociados con formas canónicas de expresión como la historia, la poesía, el teatro o la novela.

Los problemas de conservación y reedición de los periódicos tempranos se deben también al tipo de consumo para el que estaban previstos inicialmente, es decir, circular, ser compartidos, y, en el caso de las hojas más noticieras, acabar no sirviendo "más que para papel viejo" (Regañón y el Nuevo Regañón, 1965, p. 37), pese a que la presencia de introducciones y de índices de materias que facilitan la consulta de los números reunidos en tomos ${ }^{1}$, apunta a una vocación enciclopédica netamente libresca de gran parte de esta producción.

Resulta inútil insistir entonces en que estos acondicionamientos, propios de la actividad periodística temprana en general, que fueron agudizados en Hispanoamérica, han tenido como consecuencia huecos en las series, con números faltantes o dispersos en lugares apartados y, a menudo, roídos por la humedad y las polillas, a pesar de haberse impuesto el uso de un papel de alta calidad, exclusivamente importado de la metrópoli en las colonias ultramarinas de España. Aparte de la dificultad de localización de los ejemplares en archivos y bibliotecas, no son pocos los investigadores que han tenido que pasar por etapas onerosas para lograr ver los textos y conseguir reproducciones aceptables que permitan un trabajo fino

1 Correspondientes a ciclos de 4, 6, 12 meses. 
de lectura, en la calma de un espacio personal de trabajo ${ }^{2}$. El Estudio histórico del periodismo guatemalteco de Barrios y Barrios (2003) se hace eco de este problema, pero aún en una fecha más reciente otro estudioso lamenta los obstáculos con los que se enfrentó su investigación doctoral: "El rastreo de la Gaceta de Guatemala", confiesa Hernández Pérez (2015),

[r]esultó un trabajo difícil, debido a que las universidades y archivos de Guatemala, Centroamérica, Estados Unidos de América y España, al momento de iniciar la investigación, no poseían la publicación. Esto implicó el que centrara mi búsqueda en la ciudad de México, lo cual después de un arduo trabajo de campo logré localizarla en la Hemeroteca de la Universidad Nacional Autónoma de México (Sala de Microfilmes). (pp. 13-14)

Los documentos estaban de hecho allí, en "universidades y archivos de Guatemala, Centroamérica, Estados Unidos de América y España", desde hace muchos decenios, pero la información de cómo llegar a ellos se hallaba dispersa.

En los últimos años, tanto en Centroamérica como en el resto de Occidente, todo indica que el problema de acceso a los periódicos antiguos está siendo resuelto, gracias a las operaciones de digitalización y puesta en línea del material. Bastante queda todavía por hacer, pero también es cierto que un breve balance de la situación actual no está de más para el investigador que se inicia en el tema ${ }^{3}$.

\section{Recursos digitales fuera del ámbito hispano}

Con la prensa periódica estamos frente a textos que tuvieron inicialmente tiradas limitadas y quedan, por lo tanto, pocos números en circulación. Basándose en Guinard (1973), Clément (1997) menciona los 1.390 ejemplares del Espíritu de los diarios y los 500 de las Cartas críticas periódicas, por recordar solo dos de los periódicos peninsulares que nombra el estudioso francés. Añade que, en lo que concierne al Mercurio peruano, caso de mayor éxito en la producción hispanoamericana del momento, es probable que las tiradas fluctuaran entre 400 y 575 ejemplares. Como series, los periódicos contaron a menudo con un volumen tan considerable de folios que resultan de difícil adquisición para individuos aún en sus reediciones modernas. Sin entrar en el caso de los papeles de mayor circulación en el siglo XVIII europeo (como las 32.781 páginas de la Gazette de Leyde), solo basta mencionar las 10.429 páginas de las Gacetas de México de Manuel Antonio Valdés (1784-1809), las 3.568 páginas del Mercurio peruano (17911795) (Clément, 1997) o las 2.168 del Papel periódico de la ciudad de Santa Fe

2 En este contexto merece una mención especial de agradecimiento la atención irreprochable del personal de la Academia de Geografía e Historia de Guatemala.

3 El presente panorama corresponde a datos recolectados hasta principios de 2017 y no tiene pretensiones de exhaustividad. 
de Bogotá (1791-1797) (Bohórquez Colorado, 1978). En estas circunstancias, la posibilidad de disponer de copias numéricas supone una insuperable aportación práctica al campo de estudios.

Fuera del ámbito hispano, se dispone de recursos importantes para acceder a versiones numéricas de periódicos anglo, franco e italohablantes, cuya consulta resulta necesaria para reconstruir el horizonte discursivo, a la vez formal, pragmático y temático, de la prensa de antiguo régimen en el mundo occidental. Se puede citar el archivo de prensa de Google, aunque este proyecto iniciado en 2008 se suspendió en 2011 (Belga News, 2011), y el British Newspaper Archive, herramienta particularmente eficaz para prensa británica. Una mención particular se merece también el programa del Centro de estudios del siglo XVIII de la Universidad de Lyon, en Francia, con sus Gazettes européennes du 18e siècle. A esta breve lista de recursos generales, habría que añadir la biblioteca digital de la asociación de bibliotecas e instituciones de investigación Hathi Trust, así como Internet Archive: ambos casos proveen copias digitales de importantes periódicos hispanos, aunque no sea éste un aspecto específico de su compromiso. En esta lista se pueden incluir otros recursos digitales para el ámbito de la francofonía, como Media 19 (para prensa francófona decimonónica de las Antillas, Bélgica, Canadá y Québec, Egipto, Estados Unidos, Francia, Grecia, India, México, Suiza, Uruguay); están también disponibles colecciones de antiguos periódicos canadienses, franco y anglo hablantes, en Notre mémoire en ligne de Canadiana.org, así como revistas y periódicos quebequenses de bibliotecas y archivos de Québec. Finalmente (aunque siempre a título provisional) resulta útil el sitio I Giornali in Italia.

\section{Recursos digitales}

\begin{tabular}{|l|l|}
\hline Google News & https://news.google.com/newspapers \\
\hline British Newspaper Archive & http://www.britishnewspaperarchive.co.uk \\
\hline Gazettes européennes du 18e siècle & http://www.gazettes18e.fr \\
\hline Hathi Trust Digital Library & https://www.hathitrust.org/digital_library \\
\hline Internet Archive & https://archive.org \\
\hline Medias 19 & http://www.medias19.org \\
\hline Notre mémoire en ligne - Canadiana.org & http://eco.canadiana.ca \\
\hline $\begin{array}{l}\text { Bibliothèques et archives nationales du } \\
\text { Québec }\end{array}$ & $\begin{array}{l}\text { http://www.banq.qc.ca/collections/collec- } \\
\text { tion_numerique/journaux-revues/index. } \\
\text { html?ListeTitreOn=* }\end{array}$ \\
\hline I Giornali in Italia & $\begin{array}{l}\text { http://digilander.libero.it/imiani/Ricerche/ } \\
\text { giornali\%20in\%20Italia/home.html }\end{array}$ \\
\hline
\end{tabular}

Cuadro 1. Algunos recursos digitales para prensa periódica fuera del ámbito hispano 


\section{Reediciones impresas de periódicos tempranos hispanoamericanos}

Si nos centramos ahora en el ámbito hispanoamericano, y más particularmente en la reedición de la producción periodística temprana, es probable que varias agendas nacionalistas (o gremiales) motivaran la reimpresión de los papeles más notables de la época colonial que se realizó sobre todo a partir de los años cincuenta, y particularmente en los ochenta del siglo pasado. Afortunadamente, para ello se recurrió casi exclusivamente a la edición facsímil o cercana a la facsímil, respetando por lo tanto la dinámica editorial de la prensa periódica, marcada fundamentalmente por principios de jerarquía y discontinuidad formal y en gran medida temática.

En México ${ }^{4}$, se imprime así en 1949 y 1950 una edición de las Gacetas sacadas por el obispo Castorena y Ursúa y el presbítero Sahagún de Arévalo (1722-1742), y a mediados de los años ochenta, uno de los tres primeros tomos de las Gacetas de México de Manuel Antonio Valdés. Paralelamente, se publicaban el Mercurio volante de José Ignacio Bartolache (1772-1773), y los tres primeros periódicos de José Antonio Alzate: "Diario literario de México dispuesto para la utilidad pública a quien se dedica" (1768); "Asuntos varios sobre ciencias, y artes" (1772); "Observaciones sobre la Física, Historia natural, y Artes útiles" (1787-1788) (Roberto Moreno ed., 1980, pp. 1-58; 59-150; 151-249). En cambio, no se juzgó necesario en ese momento, ni curiosamente después, realizar una edición de las Gacetas de literatura (1788-1795) del mismo Alzate que fuera más respetuosa del original que la que se había elaborado en 1831. Notemos que, mientras la American Philosophical Society de Filadelfia solo posee 10 números (1792, del 38 a 47) del segundo tomo original, gran parte de la colección se conserva en la Biblioteca Palafoxiana de Puebla, y posiblemente (aunque no lo hemos podido comprobar) en la Biblioteca Cervantina del Tecnológico de Monterrey, en México, con lo cual no habría sido (ni sería) tan difícil la labor de reedición.

En un proceso análogo al de México, en el Perú (1982-1983), se publicaban ediciones facsimilares de la Gaceta de Lima en diferentes épocas, mientras toda la serie del Mercurio peruano (1790-1795) lo había sido en 1966. Más de diez años después de esta edición, en 1978, en Colombia, se realizaba una reproducción en siete tomos de otro monumento de la época colonial, el Papel periódico de la Ciudad de Santafé de Bogotá (1791-1797) de Manuel del Socorro Rodríguez, seguida en 1993 por la del menos ambicioso Correo curioso erudito, económico y mercantil de la Ciudad de Santafé de Bogotá (1801).

4 Cuna del periodismo hispanoamericano si se considera la ambición y la continuidad de sus primeras gacetas. Sin embargo, el estudio y la transcripción del Diario de noticias sobresalientes en la Corte de Lima (1700-1705) que acaban de poner en línea Firbas y Rodríguez Garrido (2017) contribuirán al mayor reconocimiento de la aportación del Perú a la historia de la prensa. 
En el mismo período (1995), un colegio de periodistas ecuatorianos se hacía cargo de la doble edición facsimilar y moderna de la importante, aunque cuantitativamente modesta, obra de Eugenio Santa Cruz y Espejo, las Primicias de la Cultura de Quito (1792), que había sido divulgada previamente (1912), junto con otros escritos del médico quiteño.

En esta lista de reediciones de periódicos preindependentistas, no puede faltar la mención de dos papeles del Río de la Plata, el Telégrafo mercantil (1801-1802) y su sucesor inmediato, el Semanario de agricultura (1802-1807), que se valieron de ediciones facsimilares en 1914 y 1928-1937 respectivamente, con una reimpresión popular en 2003, y otra, más reciente, sobre soporte CD-Rom.

Esto deja fuera dos zonas de la monarquía española en las que la actividad periodística fue, sin embargo, particularmente dinámica en varios momentos del período que hemos seleccionado: las audiencias de Cuba y de Guatemala. Para La Habana, si bien es cierto que El Regañón y el Nuevo Regañón (1800-1802) fueron reeditados con fondos de la UNESCO en 1965, del importante Papel periódico de la Habana (1790-1804) solo se han sacado hasta ahora extractos para una antología (Vitier, 1990). Esto se debe sin lugar a dudas a la falta de medios en la Cuba actual, pero tal vez haya sido un factor adicional el lastre ideológico que supone la representación reiterada, e insoportable para el lector de hoy, de seres humanos como meras mercancías en las secciones finales de compra y venta del periódico.

En cuanto a la América Central, en lo que corresponde a un período inmediatamente posterior al considerado anteriormente, notemos en 1969 las ediciones conmemorativas (no estrictamente facsímiles) del Sesquicentenario de la Independencia de Centro América para el Amigo de la patria de José Cecilio del Valle (1954) y El Editor constitucional, del Dr. Pedro Molina (1960). Sin embargo, la anterior, y mucho más ambiciosa, Gaceta de Guatemala, que constituye otro monumento de las letras americanas, no ha recibido la atención editorial que se merece. El periódico (o más bien, un papel con este mismo título) se publicó de manera discontinua durante el siglo XVIII: entre 1729-1731, 1793-1796, 17971807, y luego de 1808 a 1816 (Poupeney-Hart, 2010). Ya a mediados del siglo XIX, se observó una reinvindicación de este legado con la transcripción, en la gaceta homónima (17 de octubre-16 de noviembre de 1857), de algunos extractos de la primera serie, que se ha preservado y se puede consultar íntegra en la Hispanic Society of New York. De la segunda serie, no quedan, parece, más que algunos ejemplares conservados en el Archivo de Indias de Sevilla. Pero la tercera serie de la gaceta, a pesar de sus casi 3.000 páginas en diez tomos, que cubren una amplia variedad de temas (costumbres, economía, historia, geografía, medicina, etnografía, lengua, poesía), no ha conocido el éxito editorial de los pocos periódicos de nivel y proyección equivalentes en el continente. Que sepamos, solo se 
ha vuelto a imprimir en Anales de la Sociedad de Geografia e Historia (1952) un ensayo intitulado "Memoria para hacer una descripción puntual del reino de Guatemala", e incorrectamente atribuido a José Domingo Hidalgo en el encabezado. Últimamente ha salido un tomo, el séptimo, publicado por Hard Press Publishing, a partir de un ejemplar digitalizado y puesto en línea por Internet Archive (s.f.).

\begin{tabular}{|c|c|c|}
\hline Autor/Título & Reimpresión & Año \\
\hline $\begin{array}{l}\text { Alzate, José Antonio. Gacetas de } \\
\text { Literatura de México, } 4 \text { vol. }\end{array}$ & $\begin{array}{l}\text { Puebla, reimpresas en la oficina del hospital } \\
\text { de S. Pedro, a cargo del ciudadano Manuel } \\
\text { Buen Abad }\end{array}$ & 1831 \\
\hline $\begin{array}{l}\text { Alzate, José Antonio. Obras. I } \\
\text { Periódicos. }\end{array}$ & $\begin{array}{l}\text { Edición de Roberto Moreno. México, } \\
\text { Universidad Nacional Autónoma de } \\
\text { México }\end{array}$ & 1980 \\
\hline $\begin{array}{l}\text { Bartolache, José Ignacio. } \\
\text { Mercurio volante, 1772-1773 }\end{array}$ & $\begin{array}{l}\text { México, Universidad Nacional Autónoma } \\
\text { de México }\end{array}$ & 1993 \\
\hline $\begin{array}{l}\text { Beteta, Ignacio. La Gazeta de } \\
\text { Guatemala... }\end{array}$ & Miami, Hard Press Publishing & s. f. \\
\hline $\begin{array}{l}\text { Correo curioso, erudito, } \\
\text { económico y mercantil de la } \\
\text { Ciudad de Santafé de Bogotá }\end{array}$ & Bogotá, Biblioteca Nacional & 1993 \\
\hline $\begin{array}{l}\text { Gazeta de Lima. De } 1756 \text { a } \\
\text { 1762. De Superunda a Amat }\end{array}$ & Edición de José Durand. Lima, COFIDE & 1982 \\
\hline $\begin{array}{l}\text { Gazeta de Lima. De } 1762 \text { a } \\
\text { 1765. Apogeo de Amat }\end{array}$ & Edición de José Durand. Lima, COFIDE & 1982 \\
\hline $\begin{array}{l}\text { Gazeta de Lima. De } 1793 \text { a junio } \\
\text { de 1794. Gil de Taboada y Lemos }\end{array}$ & Edición de José Durand. Lima, COFIDE & 1983 \\
\hline $\begin{array}{l}\text { Gacetas de México. Castorena } \\
\text { y Ursúa (1722). Sahagún de } \\
\text { Arévalo (1728 a 1742). Vol. I: } \\
1722 \text { y } 1728 \text { a } 1731\end{array}$ & México, Secretaría de Educación Pública & 1949 \\
\hline $\begin{array}{l}\text { Gacetas de México. Castorena } \\
\text { y Ursúa (1722). Sahagún de } \\
\text { Arévalo (1728 a 1742). Vol II: } \\
1732 \text { a } 1736\end{array}$ & México, Secretaría de Educación Pública & 1950 \\
\hline $\begin{array}{l}\text { Gacetas de México. Castorena } \\
\text { y Ursúa (1722). Sahagún de } \\
\text { Arévalo (1728 a 1742). Vol. III: } \\
1737 \text { a } 1742\end{array}$ & México, Secretaría de Educación Pública & 1950 \\
\hline $\begin{array}{l}\text { Gazeta de México (Enero a } \\
\text { agosto de 1784). }\end{array}$ & México-Windsor, Ont., Rolston-Bain & 1983 \\
\hline $\begin{array}{l}\text { Gazeta de México (Agosto a } \\
\text { diciembre de 1784) }\end{array}$ & México-Windsor, Ont., Rolston-Bain & 1985 \\
\hline $\begin{array}{l}\text { Gazeta de México (Enero a julio } \\
\text { de 1785). }\end{array}$ & México-Windsor, Ont., Rolston-Bain & 1986 \\
\hline
\end{tabular}




\begin{tabular}{|c|c|c|}
\hline $\begin{array}{l}\text { Hidalgo, José Domingo. } \\
\text { "Memoria para hacer una } \\
\text { descripción puntual del reino de } \\
\text { Guatemala" }\end{array}$ & $\begin{array}{l}\text { Anales de la Sociedad de Geografía e } \\
\text { Historia, Tomo XXVI, núm. 3-4, pp. } \\
\text { 383-413 }\end{array}$ & 1952 \\
\hline Mercurio peruano, 12 tomos & Lima, Biblioteca Nacional del Perú & 1966 \\
\hline $\begin{array}{l}\text { Molina, Dr. Pedro. El Editor } \\
\text { constitucional, } 3 \text { tomos }\end{array}$ & $\begin{array}{l}\text { Guatemala, Editorial del Ministerio de } \\
\text { Educación Pública }\end{array}$ & $\begin{array}{l}1954, \\
1969\end{array}$ \\
\hline $\begin{array}{l}\text { Papel Periódico de Santa Fe de } \\
\text { Bogotá }\end{array}$ & $\begin{array}{l}\text { Bogotá, Banco de la República-Biblioteca } \\
\text { Nacional }\end{array}$ & 1978 \\
\hline Regañón y el Nuevo Regañón, El & $\begin{array}{l}\text { La Habana, Comisión Nacional Cubana de } \\
\text { la UNESCO }\end{array}$ & 1965 \\
\hline $\begin{array}{l}\text { Santa Cruz y Espejo, Francisco } \\
\text { Javier Eugenio. Escritos del } \\
\text { Doctor Francisco Javier Eugenio } \\
\text { Santa Cruz y Espejo. Tomo } \\
\text { primero }\end{array}$ & Quito, Imprenta Municipal & 1912 \\
\hline $\begin{array}{l}\text { Santa Cruz y Espejo, Francisco } \\
\text { Javier Eugenio. Primicias de la } \\
\text { Cultura de Quito }\end{array}$ & Quito, Colegio de Periodistas de Pichincha & 1995 \\
\hline $\begin{array}{l}\text { Semanario de agricultura, } \\
\text { industria y comercio (1802- } \\
\text { 1807), } 5 \text { vol. }\end{array}$ & Buenos Aires, Gmo. Kraft & $\begin{array}{l}1928- \\
1937\end{array}$ \\
\hline $\begin{array}{l}\text { Semanario de agricultura, } \\
\text { industria y comercio (1802- } \\
\text { 1807), } 5 \text { vol. Juan Hipólito } \\
\text { Vieytes }\end{array}$ & $\begin{array}{l}\text { Buenos Aires, Biblioteca testimonial del } \\
\text { bicentenario-Editorial Docencia }\end{array}$ & 2003 \\
\hline $\begin{array}{l}\text { Telégrafo mercantil, rural, } \\
\text { político-económico e } \\
\text { historiográfico del Río de la } \\
\text { Plata } 1801-1802,2 \text { vol. }\end{array}$ & $\begin{array}{l}\text { Buenos Aires, Junta de Historia y } \\
\text { Numismática Americana }\end{array}$ & 1914 \\
\hline $\begin{array}{l}\text { Telégrafo mercantil, rural, } \\
\text { político-económico e } \\
\text { historiográfico del Río de } \\
\text { la Plata } 1801-1802,4 \text { vol. } \\
\text { Francisco Cabello y Mesa }\end{array}$ & $\begin{array}{l}\text { Buenos Aires, Biblioteca testimonial del } \\
\text { bicentenario-Editorial Docencia }\end{array}$ & 2003 \\
\hline $\begin{array}{l}\text { Valle, José Cecilio del. El Amigo } \\
\text { de la patria, } 2 \text { tomos }\end{array}$ & Guatemala, Editorial José de Pineda Ibarra & 1969 \\
\hline $\begin{array}{l}\text { Vitier, Cintio et al. La literatura } \\
\text { en el Papel periódico de la } \\
\text { Havana } 1790-1805\end{array}$ & La Habana, Editorial Letras Cubanas & 1990 \\
\hline
\end{tabular}

Cuadro 2. Reediciones impresas citadas 


\section{Recursos y ediciones digitales de periódicos hispanoamericanos tempranos}

Si consideramos ahora la edición numérica, ya se mencionó que Hathi Trust, Google e Internet Archive dan acceso a varios títulos importantes, pero desde la península ibérica se ha realizado un trabajo particularmente digno de celebrarse: la Hemeroteca digital de la Biblioteca Nacional de España (BNE) se ha vuelto un recurso fundamental, al que se debe añadir, en menor medida, la Biblioteca virtual Miguel de Cervantes, así como la Biblioteca digital de la Agencia Española de Cooperación Internacional para el Desarrollo (BIDA-AECID). No puede faltar la mención de hemerotecas digitales nacionales o regionales: entre las más pertinentes para el asunto y el período que nos ocupa, están la Hemeroteca Nacional Digital de México (HNDM), la Hemeroteca digital histórica del Banco de la República de Colombia (BRC), y Trapalanda, Biblioteca digital de la Biblioteca Nacional de la República Argentina.

\begin{tabular}{|l|l|}
\multicolumn{1}{|c|}{ Archivos digitales } & \multicolumn{1}{c|}{ URL } \\
\hline Argentina: Trapalanda & handle//123456789/16708 \\
\hline $\begin{array}{l}\text { Colombia: BRC-Hemeroteca } \\
\text { digital histórica }\end{array}$ & $\begin{array}{l}\text { http://www.banrepcultural.org/blaavirtual/ } \\
\text { hemeroteca-digital-historica/all }\end{array}$ \\
\hline $\begin{array}{l}\text { España: BNE-Hemeroteca } \\
\text { digital }\end{array}$ & http://hemerotecadigital.bne.es \\
\hline $\begin{array}{l}\text { España: Biblioteca virtual } \\
\text { Miguel de Cervantes }\end{array}$ & http://www.cervantesvirtual.com \\
\hline España: BIDA-AECID & $\begin{array}{l}\text { http://bibliotecadigital.aecid.es/bibliodig/es/ } \\
\text { estaticos/contenido.cmd?pagina=estaticos/ } \\
\text { presentacion }\end{array}$ \\
\hline México: HNDM & $\begin{array}{l}\text { http://www.hndm.unam.mx/index.php/es/ } \\
\text { acerca-de-hndm }\end{array}$ \\
\hline
\end{tabular}

Cuadro 3. Algunos archivos digitales

Se dispone por este medio de versiones numéricas de muchos de los títulos evocados anteriormente:

\begin{tabular}{|l|l|l|}
\multicolumn{1}{|c|}{ Títulos } & \multicolumn{1}{c|}{$\begin{array}{c}\text { Archivos } \\
\text { digitales }\end{array}$} \\
\hline $\begin{array}{l}\text { Alternativo } \\
\text { del Redactor } \\
\text { Americano } 1807- \\
1809\end{array}$ & BRC & $\begin{array}{l}\text { http://www.banrepcultural.org/blaavirtual/ } \\
\text { hemeroteca-digital-historica/el-alternativo- } \\
\text { del-redactor-americano }\end{array}$ \\
\hline $\begin{array}{l}\text { Aurora. } \text { Correo de } \\
\text { la Havana } 1800- \\
1807\end{array}$ & Internet Archive & $\begin{array}{l}\text { Números sueltos, 1807: https://archive.org/ } \\
\text { details/auroracorreopoli00palm }\end{array}$ \\
\hline
\end{tabular}




\begin{tabular}{|c|c|c|}
\hline $\begin{array}{l}\text { El Aviso (de la } \\
\text { Habana) } 1805- \\
1810\end{array}$ & $\begin{array}{l}\text { Hemeroteca } \\
\text { digital BNE }\end{array}$ & $\begin{array}{l}\text { Del núm. } 64 \text { (1805) al núm. } 179 \text { (1810): } \\
\text { http://hemerotecadigital.bne.es/details. } \\
\text { vm?q=id:0026480286\&lang=es }\end{array}$ \\
\hline \multirow{3}{*}{$\begin{array}{l}\text { Diario de México } \\
1805-1817\end{array}$} & HNDM & 1805-1810 : http://www.hndm.unam.mx \\
\hline & Hathi Trust & $\begin{array}{l}\text { Tomos } 1,2,3,4,6,7,9,11 \text { : } \\
\text { https://babel.hathitrust.org/cgi/ls?a=srchls\&an- } \\
\text { yall1=all\&q1=diario+de+M\%C3\%A9xi- } \\
\text { co\&field1=ocr\&op3=AND\&yop=between\&p- } \\
\text { date_start=1750\&pdate_end=1820\&facet_- } \\
\text { lang=language\%3ASpanish\&facet_lang=\&- } \\
\text { facet_format= }\end{array}$ \\
\hline & $\begin{array}{l}\text { BNE-Hemeroteca } \\
\text { digital }\end{array}$ & $\begin{array}{l}\text { 1808-1813: http://hemerotecadigital.bne.es/ } \\
\text { details.vm?q=id:0004520130\&lang=fr }\end{array}$ \\
\hline \multirow{2}{*}{$\begin{array}{l}\text { Diario de noticias } \\
\text { sobresalientes en } \\
\text { esta Corte de Lima } \\
1700-1711\end{array}$} & $\begin{array}{l}\text { New York Public } \\
\text { Library Digital } \\
\text { Collections }\end{array}$ & $\begin{array}{l}\text { Original, 1700-1711: https:// } \\
\text { digitalcollections.nypl.org/items/3a32c020- } \\
\text { 9d09-0133-360b-00505686a51c }\end{array}$ \\
\hline & $\begin{array}{l}\text { Depósito } \\
\text { Académico } \\
\text { Digital } \\
\text { Universidad de } \\
\text { Navarra } \\
\end{array}$ & $\begin{array}{l}\text { Transcripción, 1700-1705 (vol. 1): http:// } \\
\text { dadun.unav.edu/handle/10171/43271 }\end{array}$ \\
\hline \multirow{2}{*}{$\begin{array}{l}\text { Gacetas de } \\
\text { Guatemala } 1797- \\
1807\end{array}$} & BIDA AECID & $\begin{array}{l}\text { Tomos 2, 6, 7: http://bibliotecadigital.aecid. } \\
\text { es/bibliodig/es/consulta/registro.cmd?id=937 }\end{array}$ \\
\hline & Internet Archive & $\begin{array}{l}\text { Tomo 7: https://archive.org/details/ } \\
\text { lagazetadguate00beteguat }\end{array}$ \\
\hline \multirow{4}{*}{$\begin{array}{l}\text { Gacetas de } \\
\text { literatura de } \\
\text { México } 1788-1795 \\
\text { Edición de } 1831\end{array}$} & Google Books & $\begin{array}{l}\text { Tomo 1: https://books.google.ca/books?id=Ps5 } \\
\text { pQHuxUhEC\&printsec=frontcover\&dq=gaceta } \\
\text { s+de+literatura+de+mexico+volume+1\&hl=en } \\
\& \text { sa=X\&ei=RZxGU-vZJuHNsQTU9oGICg\&v } \\
\text { ed=0CDUQ6AEwAQ\#v=onepage\&q\&f=false }\end{array}$ \\
\hline & Google Books & $\begin{array}{l}\text { Tomo 2: } \\
\text { https://books.google.ca/books?id=q9A- } \\
\text { EAAAAYAAJ\&printsec=frontcover\&d- } \\
\text { q=gacetas+de+literatura\&hl=fr\&sa=X\&re- } \\
\text { dir_esc }=y \# v=\text { onepage } \& q=\text { gacetas } \% 20 \mathrm{de} \% 20 \\
\text { literatura } \& \mathrm{f}=\text { false }\end{array}$ \\
\hline & Google Books & $\begin{array}{l}\text { Tomo 3: } \\
\text { https://books.google.ca/books?id=Ut- } \\
\text { K4AAAAIAAJ\&printsec=frontcover\&d- } \\
\text { q=gacetas+de+literatura\&hl=fr\&sa=X\&re- } \\
\text { dir_esc=y\#v=onepage\&q=gacetas } \% 20 \mathrm{de} \% 20 \\
\text { literatura\&f=false }\end{array}$ \\
\hline & Internet Archive & $\begin{array}{l}\text { Tomo 4: https://archive.org/details/ } \\
\text { gacetasdelitera00ramgoog }\end{array}$ \\
\hline
\end{tabular}




\begin{tabular}{|c|c|c|}
\hline $\begin{array}{l}\text { Gacetas de México } \\
1728-1739\end{array}$ & HNDM & http://www.hndm.unam.mx \\
\hline \multirow[b]{3}{*}{$\begin{array}{l}\text { Gacetas de México } \\
\text { 1784-1809 }\end{array}$} & $\begin{array}{l}\text { BNE- Hemeroteca } \\
\text { digital }\end{array}$ & $\begin{array}{l}\text { 1784-1809: http://hemerotecadigital.bne.es/ } \\
\text { details.vm?q=id:0004520440\&lang=es }\end{array}$ \\
\hline & HNDM & 1785-1809: http://www.hndm.unam.mx \\
\hline & Google Books & $\begin{array}{l}1795 \text { (Tomo 7): https://books.google.ca/ } \\
\text { books?id=ha22XvFjSWsC\&pg=PA377\&d- } \\
\text { q=gazeta+de+mexico\&hl=fr\&sa=X\&re- } \\
\text { dir_esc=y\#v=onepage\&q=gazeta\%20de\%20 } \\
\text { mexico\&f=false }\end{array}$ \\
\hline $\begin{array}{l}\text { Gaceta de Santa Fe } \\
\text { de Bogotá } 1785\end{array}$ & BRC & $\begin{array}{l}\text { Dos ejemplares: } \\
\text { http://www.banrepcultural.org/blaavirtual/ } \\
\text { hemeroteca-digital-historica/gazeta-de- } \\
\text { santafe-de-bogota-capital-del-nuevo- } \\
\text { reyno-1785 }\end{array}$ \\
\hline $\begin{array}{l}\text { Jornal económico } \\
\text { mercantil de } \\
\text { Veracruz } 1806\end{array}$ & HNDM & http://www.hndm.unam.mx \\
\hline $\begin{array}{l}\text { Mercurio peruano } \\
1790-1795\end{array}$ & Cervantes virtual & $\begin{array}{l}12 \text { tomos: http://www.cervantesvirtual.com/ } \\
\text { partes/222686/mercurio-peruano- }\end{array}$ \\
\hline Papel periódico de & & 12 ejemplares: \\
\hline $\begin{array}{l}\text { la Havana 1790- } \\
1805\end{array}$ & digital & $\begin{array}{l}\text { http://hemerotecadigital.bne.es/details. } \\
\text { vm?q=id:0026498316\&lang=es }\end{array}$ \\
\hline \multirow{2}{*}{$\begin{array}{l}\text { Papel periódico } \\
\text { de Santa Fe de } \\
\text { Bogotá } 1791-1797\end{array}$} & $\mathrm{BRC}$ & $\begin{array}{l}\text { A partir del original: } \\
\text { http://www.banrepcultural.org/blaavirtual/ } \\
\text { hemeroteca-digital-historica/papel-periodico- } \\
\text { santafe }\end{array}$ \\
\hline & Hathi Trust & $\begin{array}{l}\text { A partir de la edición de } 1978: \\
\text { https://babel.hathitrust.org/cgi/ } \\
\text { ls?field1=ocr;q1=papel } \% 20 \\
\text { peri\%C3\%B3dico;a=srchls;lmt=ft }\end{array}$ \\
\hline $\begin{array}{l}\text { Primicias de la } \\
\text { cultura de Quito } \\
1792\end{array}$ & Cervantes virtual & $\begin{array}{l}\text { A partir de la edición de 1912: } \\
\text { http://www.cervantesvirtual.com/servlet/ } \\
\text { SirveObras/35761630101143831754491/ } \\
\text { index.htm }\end{array}$ \\
\hline $\begin{array}{l}\text { Redactor } \\
\text { americano } \\
1806-1809\end{array}$ & $\mathrm{BRC}$ & $\begin{array}{l}\text { http://www.banrepcultural.org/blaavirtual/ } \\
\text { hemeroteca-digital-historica/el-redactor- } \\
\text { americano-periodico-del-nuevo-reyno-de- } \\
\text { granada }\end{array}$ \\
\hline
\end{tabular}




\begin{tabular}{|l|l|l|}
\hline \multirow{2}{*}{$\begin{array}{l}\text { Semanario de } \\
\text { agricultura }\end{array}$} & Trapalanda & $\begin{array}{l}\text { A partir del original: http://trapalanda.bn.gov. } \\
\text { ar/jspui/handle/123456789/16879 }\end{array}$ \\
\cline { 2 - 3 } 1802-1807 & Hathi Trust & $\begin{array}{l}\text { A partir de la edición de 1928-1937: } \\
\text { https://catalog.hathitrust.org/ } \\
\text { Record/008919443 }\end{array}$ \\
\hline $\begin{array}{l}\text { Telégrafo } \\
\text { mercantil, rural, } \\
\text { político-económico } \\
\text { e historiográfico } \\
\text { del Río de la Plata }\end{array}$ & Trapalanda & $\begin{array}{l}\text { http://trapalanda.bn.gov.ar/jspui// } \\
\text { handle/123456789/16886 }\end{array}$ \\
\cline { 2 - 3 } $\begin{array}{l}\text { 1801-1802 } \\
\text { digital hispánica }\end{array}$ & $\begin{array}{l}\text { http://bdh-rd.bne.es/viewer. } \\
\text { vm?id=0000015765\&page=1 }\end{array}$ \\
\hline
\end{tabular}

Cuadro 4. Ediciones digitales de periódicos hispanoamericanos

Entre los periódicos más importantes a los que no se tiene un acceso fácil, se encuentra uno que ha quedado completamente fuera del proceso de reimpresión: se trata del Diario de Lima, curioso, erúdito, económico y social y comercial (17901793), publicado inicialmente por Jaime Bausate y Mesa (el futuro redactor del Telégrafo mercantil del Río de la Plata, quien lo publicaría bajo su verdadero nombre de Francisco Antonio Cabello y Mesa), y conservado casi íntegro en la Biblioteca del Instituto Riva-Agüero de la Pontificia Universidad Católica del Perú, en Lima.

\section{El caso de la Gaceta de Guatemala}

El otro caso para el que no hay edición moderna impresa, y no ha sido todavía digitalizado en su integridad, es la tercera serie de la Gaceta de Guatemala (17971807). El impulso que, a raíz de la creación de la Sociedad de Amigos del País (1795), le dio el oidor Jacobo de VillaUrrutia a una versión ampliada y renovada del papel, sacado unos pocos años antes bajo este nombre por el impresor Beteta, así como el innegable talento y la excepcional energía que demostraron sus editores principales, los jóvenes y brillantes peninsulares Alejandro Ramírez y Simón Bergaño, hicieron que la publicación lograra una pertinencia notable mucho más allá de las fronteras del Reino. No se puede olvidar que entre 1797 y 1801 fue el único papel literario ${ }^{5}$ de habla española en el continente, y hasta 1805 , el único al norte de Nueva Granada. Esto explica la supervivencia del título en varias bibliotecas prestigiosas del mundo. Es así como a lo largo de los años hemos podido identificar colecciones completas o casi completas de esta serie en el Archivo de Indias, la British Library, la Biblioteca Nacional de Guatemala, la Academia de

5 No fue únicamente noticioso. 
Geografía e Historia de Guatemala, la Biblioteca Nacional de Chile. Sin hablar de la presencia de números digitalizados o microformas en otras bibliotecas universitarias de México (Hemeroteca de la UNAM) y Estados Unidos (University of Texas at Austin; John Carter Brown Library), se encuentran también los seis o siete primeros tomos en la Biblioteca Newberry de Chicago y en la American Philosophical Society de Filadelfia: ya en 1807, esta institución masónica ${ }^{6}$ había realizado una compra de seis volúmenes, después de haber aceptado al editor Alejandro Ramírez como miembro en 1801. La lista que acabamos de esbozar no es definitiva pero ilustra bien la proyección internacional que logró alcanzar en su tiempo esta publicación regional.

Ante la amenaza del cierre de la Gaceta por el presidente de la Audiencia José Domás después de un solo año de existencia de la tercera serie (1798), alegaba el impresor Beteta que, antes de su publicación,

Guatemala no representaba ningún papel en el mundo literario: aún en esta América era apenas conocido su nombre; ninguna relación tenía un reino tan considerable con los demás de este continente: sólo ocupaba lugar en la Guía y en el espíritu de sus naturales [...] Empezó este periódico, y los imparciales de dentro y fuera del reino aplaudieron su plan desde un principio. (cit. en Medina 1960, II, I, p. 305)

Estos esfuerzos no fueron obviamente suficientes para remediar el problema de la marginalidad de Guatemala y Centroamérica en general, tanto en las preocupaciones políticas y económicas internacionales como en el escenario académico hasta hoy, lo que explica sin lugar a dudas el retraso en la difusión moderna de su prensa temprana. Éste se debe también a la ausencia en el país mismo (y notablemente entre sus élites) de un dinamismo de tenor nacionalista que respaldara, entre otras iniciativas de valoración del patrimonio cultural, una operación de edición o digitalización. Se debe mencionar también la falta de apoyo institucional de parte de países más prósperos, como fue el caso en los años setenta de la microfilmación del Archivo General de Centro América promovida por la Universidad canadiense McMaster como consecuencia de la voz de alarma dada por el profesor John Browning. En la espera de que se concrete en la Universidad Autónoma Metropolitana de México un proyecto de publicación numérica del papel centroamericano encabezado por el Dr. José Santos Hernández Pérez, varios otros sitios del mundo hispano han señalado el camino a seguir y ofrecen herramientas de las que no se puede minimizar el interés.

Además de la considerable economía de costos para el público erudito y los investigadores que viven lejos de los archivos pertinentes, el acceso libre por internet

6 Fundada por Benjamin Franklin en 1743. 
a los documentos representa una mina de datos sobre el período colonial. Resulta también imprescindible para el estudio de la prensa misma en su dimensión histórica. Efectivamente no conviene considerar los periódicos de manera aislada, dado su carácter intrínseco de plataforma en (y desde) que circulan las ideas, las noticias, las expresiones de diálogo intertextual en sus modalidades particulares, implícitas y explícitas: que sean las temáticas abordadas o los formatos adoptados, que sean las colaboraciones de corresponsales locales o extranjeros, las traducciones, las citas íntegras o paráfrasis de artículos procedentes de distintos lugares.

El disponer de una amplia biblioteca digital, además de la reconstrucción del horizonte ideológico e intelectual del lectorado original, favorece también al rastreo de la producción de un autor en particular, a la reconstitución eventual de una obra individual y a su recuperación en un canon literario (en sentido amplio) nacional o regional.

Al igual que tantas publicaciones periódicas del momento, la Gaceta de Guatemala respondió al llamado de ilustración pública que movió a los sectores literatos de los países occidentales en el siglo XVIII. El prospecto del Mercurio peruano había constatado que "Entre los diversos objetos, que ocuparon las Prensas, ninguno fue mas util, que el de los Papeles Periodicos. Desde la adopción de ellos se puede casi fixar la época de la ilustracion de las Naciones" (1790). Haciéndose eco de estas palabras, añade en $1797^{7}$ el de la Gaceta de Guatemala:

La necesidad y utilidad de los periodicos se han ponderado y repetido mil veces. Es cierto que ellos han contribuido principalmente á la extensión y propagación de las luzes en Europa, y que à ellos se debe la manía o prurito de escribir, tan util para sacar á plaza los talentos ignorados, y para fomentar el entusiasmo de la gloria literaria, sin el qual, muertos, ó aletargados los ingenios, yacen en un abandono tan perjudicial á ellos mismos como al publico.

En Guatemala mas que en ninguna otra parte, es necesaria una obra de esta especie. Sin ella la Sociedad naciente no podrá prosperar, ó sus progresos, concentrados en si misma, seràn desconocidos del resto del mundo. ("Prospecto de ampliación")

Este objetivo de ilustración y progreso no se alcanzaría sin apertura a múltiples facetas de una realidad sobre la que se podía (y se tenía la obligación moral de) actuar, en beneficio no solo de la Patria, sino de la humanidad, y sin participación en intercambios de ideas más allá de las fronteras políticas y lingúísticas. Si resulta tan importante para la investigación sobre periodismo antiguo, en general, y sobre la Gazeta de Guatemala, en particular, el tener acceso a la integridad de una multiplicidad de escritos contemporáneos es que ella encarna, más que cualquier publicación del momento en Hispanoamérica este ideal de diálogo intelectual

$7 \quad$ O a finales de 1796. 
con sabios de los horizontes más diversos (la República de las letras) a través del vehículo más eficaz que se concibe en el momento ${ }^{8}$ : la prensa periódica.

Como queda claro tanto en 1793 (Medina 1960, pp. 299-300), como en 1797 ("Prospecto de ampliación"), la publicación se inspira directa y explícitamente en otro papel, el Mercurio peruano. Coincidentemente, dos personajes claves en la historia de la publicación limeña se encontraban en el Reino en ese momento, y tanto su temperamento como su experiencia afectaron la Gaceta: se trata del regente Ambrosio Cerdán, responsable del último año de existencia del Mercurio como órgano de la Sociedad de Amantes del País de Lima, de la que había sido elegido presidente; y del mismo fundador del papel, José Rossi y Rubí, también presente en el Istmo tras su nombramiento en 1794 como alcalde mayor de Suchitepéquez. Mientras el primero confirmó en su nueva función el talante conservador de su ideología y obró por censurar el periódico (Poupeney-Hart 2009b), el segundo no podía menos que confirmarse como colaborador excepcional en su defensa del indígena y, particularmente, interlocutor predilecto de los editores. De todos los mercuristas, Rossi había sido el que manifestó el mayor interés por el periodismo como fenómeno textual y más ampliamente cultural. Ya desde el "Prospecto", firmado por Jacinto Calero y Moreira pero redactado por él, había ofrecido a los suscriptores potenciales una visión de conjunto de esta nueva forma de expresión pública. Volvería sobre el asunto en más de una ocasión, además de encargarse de mantener a sus lectores al tanto de nuevas publicaciones periódicas. Esta dimensión metadiscursiva de Mercurio se pierde con la salida de su "padre" para España. Se pierde en el Perú pero alimentará una empresa análoga: Alejandro Ramírez y Simón Bergaño lograron así integrar, tal vez mucho mejor que en el papel peruano, las estrategias dialógicas preconizadas por Rossi e inspiradas en prestigiosas publicaciones europeas como el británico The Spectator.

Las relaciones de la Gaceta de Guatemala con otros periódicos no paran ahí : además de haber servido el papel guatemalteco durante varios años como conducto para comunicar al mundo trabajos de sabios novohispanos (Clavijero, Mociño, entre otros) (Poupeney-Hart, 2014), es aprovechado también en papeles contemporáneos tanto americanos (la Aurora de la Habana, la Gaceta y el Diario de México), como peninsulares (el Semanario de agricultura y arte, el Correo mercantil de España y sus Indias) (Poupeney-Hart, 2015).

Por otra parte, si se modifica el enfoque analítico, pasando de la publicación en su conjunto a la obra individual de sus autores, llama particularmente la atención la experiencia en este campo de las tres figuras fundamentales de la empresa: Jacobo de VillaUrrutia, Alejandro Ramírez y Simón Bergaño. Sabemos, por ejemplo, que

8 Como ahora internet. 
el oidor VillaUrrutia estuvo vinculado con dos empresas periodísticas previa y posteriormente a su experiencia con la Gaceta: una colaboración con el Diario de los ciegos o de Madrid, y la cofundación del Diario de México, junto con Carlos María Bustamante. Ramírez, luego de su salida de Centroamérica, aprovechó su puesto de intendente en Puerto Rico para sacar a la luz otro periódico que sirviera de portavoz de las ideas y programas de una nueva sociedad económica, el Diario económico de Puerto Rico (1814-1815). Simón Bergaño, finalmente, no dejó sus actividades poéticas ni periodísticas al ser condenado al destierro en 1808; y al encontrarse en Cuba de donde seguía remitiendo poemas al Diario de México, fundó o colaboró con varios periódicos locales: el Aviso (1809), el Correo de las Damas (1811), el Patriota americano (1812), El Diario cívico (1812), El Esquife (1813-1814). Esto por mencionar las figuras más sobresalientes del proyecto.

A la vista de este panorama, no dudamos que el completarse el proceso de digitalización de la prensa temprana permitirá realzar una faceta particularmente alentadora de la historia de Centroamérica y enriquecerá la apreciación de su patrimonio cultural.

\section{Referencias}

Barrios y Barrios, C. (2003). Estudio del periodismo guatemalteco (Época colonial y Siglo XIX). Guatemala, Universidad de San Carlos de Guatemala-Editorial Universitaria.

Bélaubre, C. (2008). "Bergaño y Villegas, Simón”. Diccionario de la Asociación para el Fomento de los Estudios Históricos en Centramérica. Recuperado de http://afehc-historia-centroamericana.org/index. php?action $=$ fi_aff\&id $=1841$

Belga News. 2011. "Google arrête la numérisation des archives de journaux". Recuperado de https://www.rtbf.be/info/medias/detail_google-annonce-l-arret-de-la-numerisation-d-archives-de-journaux $\mathrm{id}=6141783$

Beteta, I. (1797). "Proyecto de ampliación", Gazeta de Guatemala, Tomo I. Desde 13 de Febrero de 1797 hasta 1 de Enero de 1798. [Guatemala, Imprenta de] Ignacio Beteta.

Bohórquez Colorado, J. I. (1978). "Presentación”. En Índice analítico de 'Papel periódico de la Ciudad de Santafé de Bogotá' 1791-1797. T. VII. Bogotá : Banco de la República (s.p.)

Calero y Moreira, J. (1790). "Prospecto del Papel Periódico intitulado Mercurio Peruano, de Historia, Literatura, y Noticias públicas, que a nombre de una Sociedad de Amantes del País, y como uno de ellos promete dar a luz don Jacinto Calero y Moreira". En Mercurio peruano", t. I. [Lima], Imprenta 
Real de los Niños Expósitos. Recuperado de http://www.cervantesvirtual. com/obra-visor/mercurio-peruano--15/html/027f4668-82b2-11df-acc7002185ce6064_7.htm

Clément, J.-P. (1997). El Mercurio Peruano. 1790-1795. Vol. I : Estudio. Frankfurt, Vervuert-Madrid, Iberoamericana.

Firbas, P. y J. A. Rodríguez Garrido. (2017). "El Diario de noticias sobresalientes en Lima y Noticias de Europa (1700-1711 en su contexto histórico y editorial", Diario de noticias sobresalientes en Lima y Noticias de Europa (1700-1711), Vol. 1 (1700-1705), New York, IDEA, pp. 9-46. Recuperado de http://dadun.unav.edu/handle/10171/43271

Gaceta de Guatemala. (1857). Tomo IX. Recuperado de https://archive.org/ details/gacetadeguatemal1100guat

Hernández Pérez, J. S. (2015). La 'Gaceta de Guatemala': un espacio para la difusión del conocimiento científico (1797-1804). México, Universidad Autónoma Metropolitana-Universidad Nacional Autónoma de México.

McMaster University Library. Archives and Research Collections. "Fonds RC0831 - Archivo General de Centro America fonds". Recuperado de http://archives.mcmaster.ca/index.php/archivo-general-de-centro-america-fonds

Medina J. T. (1960). La imprenta en Guatemala. Guatemala, Tipografía Nacional, T.II, vol. II.

Poupeney-Hart, C. (2009a). "Hacia una cartografía ideológica de la Ilustración americana: los pliegues de la escritura en el Mercurio peruano", Revista de crítica literaria latinoamericana, Núm. 70, pp. 165-182

Poupeney-Hart, C. (2009b). "Rossi y Rubí de Cervera, José Justiniano". Diccionario de la Asociación para el Fomento de los Estudios Históri$\cos$ en Centramérica. http://afehc-historia-centroamericana.org/index. php?action=fi_aff\&id $=2130 \mathrm{Je}$

Poupeney-Hart, C. (2009c). "Villaurrutia, Jacobo de". Diccionario de la Asociación para el Fomento de los Estudios Históricos en Centramérica. http:// afehc-historia-centroamericana.org/index.php?action=fi_aff\&id=2194

Poupeney-Hart, C. (2010). "Entre gaceta y 'espectador': avatares de la prensa antigua en América central", Cuadernos de Ilustración y Romanticismo, Núm. 6, pp. 1-22. http://revistas.uca.es/index.php/cir/article/view/195

Poupeney-Hart, C. (2014). "Prensa temprana, entre Lima, Guatemala y México (1700-1807)". En C. Poupeney-Hart, A. Navarro y G. Bastin (ed.). Ilustrar 
la nación. La prensa temprana en el mundo atlántico. París, Le Manuscrit, 2014, pp 15-55.

Poupeney-Hart, C. (2014). "Prensa temprana, entre Lima, Guatemala y México (1700-1807)”. En C. Poupeney-Hart, A. Navarro y G. Bastin ed.). Ilustrar la nación. La prensa temprana en el mundo atlántico. París, Le Manuscrit,2014,pp. 15-55

Poupeney-Hart, C. (2015). "Las luces centroamericanas en Europa: la Gazeta de Guatemala" y el "Correo mercantil de España y sus Indias (1792-1808)", Boletín AFEHC, Núm.63. Recuperado de http://afehc-historia-centroamericana.org/index.php?action=fi_aff\&id=3904

Regañon y el Nuevo Regañon (El). (1965). La Habana, Comisión Nacional Cubana de la UNESCO. 